\title{
O despertar de novos profissionais da saúde através da educação básica: uma revisão narrativa
}

\author{
The awakening of new health professionals through basic education: a narrative review \\ El despertar de nuevos profesionales de la salud a través de la educación básica: una \\ revisión narrativa
}

\begin{abstract}
Lázaro Saluci Ramos ${ }^{1 *}$, Flora Karoline Galito Gonçalves Santos², Mariane Jordão Valpasso², Emanuelly Moreira Alves², Rosângela de Fátima Almeida Lunz Costalonga², Kitia Luzia Cruz Ferreira $^{2}$, Katia Cruz Ferreira Pinto ${ }^{2}$, Andréa dos Santos Guimarães ${ }^{2}$, Rejane Fernandes das Neves², Renata dos Santos Ribeiro Guzman³.
\end{abstract}

\section{RESUMO}

Objetivo: Objetiva-se nessa revisão, apresentar ideias que fortaleçam a educação básica no sentido de despertar nos alunos o desejo pela atuação na saúde, como forma de ampliar o quadro profissional da área. Revisão Bibliográfica: A saúde brasileira enfrenta constante problemas devido à ausência de profissionais dedicados e inclinados aos desafios lançados pelas suas demandas. O Brasil conta com uma parcela significativa da sua população vivendo em áreas de difícil acesso, e nem todos os profissionais estão dispostos a enfrentar esses desafios, o que torna a atividade do Estado de garantir a saúde a todos um problema sério. Ampliar o conhecimento prévio, incentivar a busca pela profissão, faria com que áreas que são completamente carentes de profissionais fossem preenchidas. A educação básica brasileira conta com um amplo espaço para que os primeiros passos e os primeiros incentivos sejam dados, o que a torna terreno fértil para despertar novos profissionais, com desejo pelas profissões da área e dispostos a enfrentar desafios. Considerações Finais: $O$ estudo se baseia nos princípios educacionais voltados a criar cidadãos dispostos a colaborar com o bem comum, e como é importante abrir as portas da educação básica para conhecimentos que permitam o aluno interagir com o profissionalismo.

Palavras-chave: Educação e saúde, Educação em saúde, Saúde na escola.

\begin{abstract}
Objective: The objective of this review is to present ideas that strengthen basic education in order to awaken in students the desire to work in health, as a way to expand the professional framework of the area. Bibliographic Review: Brazilian health faces constant problems due to the absence of dedicated professionals and inclined to the challenges posed by their demands. Brazil has a significant portion of its population living in areas of difficult access, and not all professionals are willing to face these challenges, which makes the activity of the State to guarantee health for all a serious problem. Expanding prior knowledge, encouraging the search for the profession, would cause areas that are completely lacking in professionals to be filled. Brazilian basic education has ample space for the first steps and the first incentives to be taken, which makes it a fertile ground to awaken new professionals, with a desire for the professions in the area and willing to face challenges. Final Considerations: The study is based on educational principles aimed at creating citizens willing to collaborate with the common good, and how important it is to open the doors of basic education to knowledge that allows the student to interact with professionalism.
\end{abstract}

Keywords: Education and health, Health education, School health.

\footnotetext{
${ }^{1}$ Faculdade Multivix (MULTIVIX), Cachoeiro de Itapemirim - ES. *E-mail: lazaro321123@gmail.com

2 Faculdade Vale do Cricaré (FVC), São Mateus - ES.

${ }^{3}$ Facultad Interamericana de Ciencias Sociales (FICS), Assunção - PAR.
} 


\section{RESUMEN}

Objetivo: El objetivo de esta revisión es presentar ideas que fortalezcan la educación básica para despertar en los estudiantes el deseo de trabajar en salud, como una forma de expandir el marco profesional del área. Revisión Bibliográfica: La salud brasileña enfrenta problemas constantes debido a la ausencia de profesionales dedicados e inclinados a los desafíos planteados por sus demandas. Brasil tiene una porción significativa de su población que vive en áreas de difícil acceso, y no todos los profesionales están dispuestos a enfrentar estos desafíos, lo que hace que la actividad del Estado para garantizar la salud para todos sea un problema grave. Ampliar el conocimiento previo, alentando la búsqueda de la profesión, provocaría que se cubrieran áreas que carecen por completo de profesionales. La educación básica brasileña tiene un amplio espacio para los primeros pasos y los primeros incentivos a tomar, lo que lo convierte en un terreno fértil para despertar a nuevos profesionales, con un deseo por las profesiones en el área y dispuestos a enfrentar desafíos. Consideraciones Finales: El estudio se basa en principios educativos destinados a crear ciudadanos dispuestos a colaborar con el bien común, y lo importante que es abrir las puertas de la educación básica al conocimiento que le permita al estudiante interactuar con profesionalismo.

Palabras clave: Educación y salud, Educación en salud, Salud escolar.

\section{INTRODUÇÃO}

Os diferentes conceitos de promoção da saúde podem ser divididos em duas categorias: uma é comportamental e a outra, relacionada à qualidade de vida. Em primeiro lugar, a promoção da saúde inclui atividades que visam mudar o comportamento dos sujeitos, com ênfase nos componentes educacionais, que envolvem principalmente componentes educacionais relacionados à mudança de riscos comportamentais.

O segundo é baseado no seguinte entendimento: a saúde é o produto de muitos fatores relacionados à qualidade de vida, incluindo padrões adequados de alimentação, nutrição, moradia e higiene; trabalho; receber educação ao longo do ciclo da vida; ambiente físico limpo; estilo de vida responsável e assistência médica adequada (SILVA JP, et al., 2018).

O início do século XX marcou o início sistemático da introdução de métodos de educação em saúde nos currículos escolares. No momento, identificamos muitos fatores históricos dentro e fora dos campos da saúde e educação.

Exemplos de fatores internos no campo da saúde incluem: o desenvolvimento de descoberta bacteriana ao longo do século XIX; ao tentar entender a doença por causalidade, enfatizou-se o impacto da doença e do pensamento positivista; a influência do relatório Flexner em 1910 influenciou bastante a medicina no século XX. O treinamento defende o uso de métodos científicos rigorosos, ignorando a relevância de fatores sociais no processo de compreensão de doenças em saúde (MARTINS I, 2019).

Esses fatores formam a base dos pontos de vista da educação em saúde pelos higienistas, sendo que a melhoria das condições sanitárias é considerada o principal fator na eliminação de surtos de doenças e geralmente está presente nos documentos que orientam as práticas de saúde nas escolas.

Ao controlar o espaço e o corpo como uma maneira de criar condições de aprendizado, essa visão tem visões opostas na visão educacional que valoriza a ordem e a disciplina. Dá-se, portanto, a importante de introduzir a educação em saúde no currículo básico nacional, vistas as importantes descobertas e os benefícios que as disciplinas da área de ciências, biologia, química e física promoveram nas escolas (MARTINS I, 2019).

O estabelecimento da Oitava Assembléia Nacional de Saúde e da Comissão Nacional de Reforma da Saúde na década de 1980 foi crucial para muitas conquistas na reestruturação do sistema de saúde no Brasil. Apesar de muitos conflitos e interesses diferentes, ocorreram mudanças importantes, atingindo a Constituição Federal Brasileira de 1988, que reconhece a saúde como direito de todos os cidadãos e obrigação do Estado e institui o Sistema Único de Saúde (SUS). 
Ao longo dos anos, foram treinados profissionais de saúde que atuam no sistema, que incluem várias estratégias operacionais, como as Normas Operacionais de Assistência à Saúde (NOAs), Normas Operacionais Básicas (NOBs) e alcance do Tratado de Gestão.

Algumas estratégias importantes para a reorganização e humanização do sistema foram implementadas. Isso inclui Estratégia de Saúde da Família, Política Nacional de Humanização, Plano de Humanização para o Pré-Natal e o Nascimento (PHPN) e etc (BATISTA KBC e GONÇALVES OSJ, 2011).

O Programa Saúde na Escola (PSE) é uma política intersetorial no Brasil, formulado em 2007 como resultado da cooperação entre o Ministério da Saúde e o Ministério da Educação, com o objetivo de promover ações para melhorar a saúde dos alunos do sistema público de ensino, prevenir e cuidados de saúde.

As escolas participantes do PSE devem incluir os temas das atividades de saúde em seus projetos de educação política, os professores devem discutir esses tópicos na sala de aula e ser assistidos por profissionais de saúde do departamento básico de saúde.

É ideal e necessário incluir atividades de promoção da saúde no ambiente escolar. Pois isso visa melhorar o conhecimento e desenvolver habilidades para que as pessoas possam escolher comportamentos saudáveis e até mesmo despertar a aptidão dos alunos para atuar na área no futuro (OLIVEIRA FPSL, et al., 2018).

O objetivo da revisão foi abordar sobre a necessidade de formar cidadãos com aptidão para a saúde pública e que desejem atuar na área, com esse incentivo e a base do conhecimento em questão, partindo da educação básica, já que se trata do principal canal existente entre o Estado e as futuras gerações.

Para abordar esse assunto, é necessário buscar embasamento na literatura existente e construir um laço entre disciplinas que trabalham temas de saúde e como isso pode influir na construção da vocação do discente. Será necessário de igual modo, buscar o fundamento do direito fundamental à saúde, para justificar a necessidade de se trabalhar este assunto.

\section{REVISÃO BIBLIOGRÁFICA}

Nos tempos modernos, os pilares da dominação, ordem e lógica formal dominam a estrutura da ciência e da sociedade. Tudo é de se esperar. Ir à escola é privilégio da minoria, e as mulheres fora de casa raramente trabalham. Algumas jovens privilegiadas podem ser professoras ou enfermeiras, enquanto as jovens das classes menos populares trabalhavam como empregadas domésticas em casas de famílias mais ricas ou em fábricas de tecidos que já existiam em meados do século 20 .

A modernidade fez progressos inegáveis em problemas de saúde, expectativa de vida imprevisível e uso de novas tecnologias para fornecer melhores serviços; no entanto, devido à complexidade do mundo atual, discussões e práticas baseadas em modelos biomédicos não conseguem mais lidar com a nova realidade (MAINARDI N, 2010).

Políticas e programas de saúde pública e educação são essenciais para o treinamento do cidadão e a melhoria da qualidade de vida e saúde das pessoas. Uma educação melhor está relacionada a pessoas mais saudáveis, assim como as pessoas saudáveis têm maior probabilidade de apropriar-se de conhecimentos da educação formal e não formal.

Além de transmitir conhecimento sobre saúde, a escola também é organizada em disciplinas. No processo de aquisição de habilidades que apoiam a aprendizagem ao longo da vida, ela também deve educar e desenvolver valores e atitudes críticas relacionadas às realidades e estilos de vida sociais, além de apoiar a autonomia e fortalecer a promoção da saúde (LOPES IE, et al., 2018).

Considerando os hábitos formados na infância e adolescência, é provável que atitudes e crenças continuem na idade adulta, e ainda que a maioria das crianças e adolescentes no Brasil estudam (98,6\% das crianças brasileiras de 6 a 14 anos, e correspondente a 15 a 17 anos 85,0\%), encontramos um lugar privilegiado na comunidade escolar que pode realizar ações de prevenção, instrução e incentivo (LOPES IE, et al., 2018). 
O objetivo da promoção da saúde no ambiente escolar é utilizar uma ampla gama de áreas de ação para superar o modelo biomédico, que devem considerar a dimensão política, o desenvolvimento de habilidades individuais e coletivas, a participação da comunidade, o cuidado com o meio ambiente e o reposicionamento de serviços à saúde.

Essa natureza dinâmica e complexa requer treinamento profissional para facilitar o desenvolvimento de capacidades para formular e colocar em prática por meio da reflexão contínua sobre as contradições no ambiente e as necessidades de enfrentar os desafios e expectativas das comunidades no território, além de facilitar os princípios teóricos e metodológicos (TAVARES MFL, et al., 2016).

O trabalho em saúde pode ser uma fonte de satisfação ou insatisfação, afetando diretamente a vida de profissionais e cuidados médicos. No mundo de hoje, além do aumento do desemprego e do subemprego, a insatisfação daqueles que continuam trabalhando também está aumentando. A literatura documenta fatores que causam insatisfação com o trabalho em saúde e o escopo da Atenção Primária à Saúde (APS).

Isso inclui: trabalhar em locais diferentes da sua escolha, sobrecarga de trabalho e violência; conflitos e problemas de gestão do trabalho na estrutura da organização de serviços; condições salariais insuficientes, carga de trabalho excessiva e nenhum plano de carreira e deslocamentos difíceis (SORATTO J, et al., 2017).

Para a gestão e prestação de serviços de saúde em todos os países, nem sempre é possível obter profissionais qualificados com habilidades suficientes e habilidades relevantes para alocá-los a locais onde são necessários, motivados, participando e apoiando, o que é essencial para a realização e gestão dos serviços de saúde em todos os países. Por sua vez, é determinado por políticas e práticas que definem a quantidade atribuída, suas qualificações e condições de trabalho.

Para buscar atender essas necessidades, faz-se necessário encontrar profissionais ambientados com as necessidades da área, e despertar essas necessidades no ser humano não é um caminho simples. Trata-se de uma realidade pouco discutido, contudo, necessária, principalmente nas escolas, onde na maioria das vezes acontece o primeiro contato do ser humano com as ciências complexas (OLIVEIRA APC, et al., 2017).

A educação em saúde, que por muito tempo desenvolveu esse papel, ainda necessita de mais espaço e carece de engajamento para buscar atender as demandas profissionais da área. No Brasil, muito recentemente o programa Mais Médicos, alvo de críticas intensas, foi aplicado em decorrência da carência de profissionais brasileiros que se disporiam a atender regiões de difícil localização e com zelo pelo paciente.

A medicina brasileira, que em termos salariais é valorizada, foi elitizada e colocada de maneira inacessível quando o problema não está em zonas urbanas e de fácil acesso. Apesar da complexidade e da responsabilidade que esses profissionais carregam, o juramento feito ao fim da graduação nem sempre é colocado em prática (COMES Y, et al., 2016).

\section{Como trabalhar saúde na educação básica despertando vocação nos alunos}

A escola é um local para os alunos desenvolverem atividades sociais, e ao longo dos anos passaram a maior parte do tempo difundindo o bom senso, desenvolvendo sua educação, caráter e cultura e, assim, formando cidadãos. Nesse caso, a educação é um fator importante para promover e proteger a saúde das pessoas devido à capacidade receptiva dos alunos e ao seu crescimento e desenvolvimento físico e mental, é necessário realizar essas intervenções durante o semestre.

A educação é extensa e essas ações podem ser tomadas para estabelecer uma nova cultura da saúde, negando a premissa de que a educação está relacionada apenas às escolas e a saúde está relacionada aos serviços de saúde (OLIVEIRA RS, et al., 2018).

Desde a Carta de Ottawa (cerca de trinta anos atrás), o conceito de promoção da saúde como estratégia para lidar com múltiplos impactos na saúde humana foi estabelecido como uma das propostas mais promissoras em ciências da saúde, e suas ações estão vinculadas a esse conceito. Surgir para expandir a saúde, articular conhecimentos científicos e empíricos e mobilizar recursos em ações entre agências para gerar resolutividade. 
Quando existem fatores de risco, as principais medidas preventivas desempenham um papel importante, porque tentam impedir que o indivíduo fique doente e controlam os fatores de risco; portanto, trabalham no estágio pré-patogênico ou no estágio de saúde ou suscetibilidade do indivíduo (RODRIGUES DA, et al., 2015).

Antes de tudo é preciso entender os desafios inerentes ao mundo do trabalho: esses desafios são afetados por inúmeras mudanças rápidas desde o século XX e continuam a evoluir no processo de desenvolvimento contínuo de hoje, resultando em uma tarefa complexa, cujo impacto afeta diretamente os resultados acadêmicos. $\mathrm{Na}$ descrição do conhecimento sistemático do mundo em que vivemos fala-se sobre profissionalização e educação no campo da saúde.

Enfatiza-se que o processo de globalização e o deslumbrante ritmo científico e tecnológico da ciência e da tecnologia exigem que os seres humanos envidem maiores esforços para agrupar, absorver e adaptar-se às mudanças. Essa realidade trouxe enormes desafios às qualificações profissionais e à formação no trabalho, posição de destaque no mercado de trabalho (STUTZ BL e JANSEN AC, 2006).

Um exemplo de ensino em saúde na educação básica foi a Escola Técnica do Sistema Único de Saúde (etsus) que é uma instituição pública criada ou "recriada" desde 1980. Sua qualificação é fornecer treinamento de qualificação para trabalhadores do ensino fundamental e médio que não receberam certificação específica de qualificação profissional.

Em particular, o primeiro lote de livros criados no âmbito do sistema de saúde já possui as características de uma escola dessa natureza em suas "Regras da Escola": o eixo metodológico da integração dos serviços de ensino, o ajuste do currículo para adaptação à situação regional e a pedagogia do trabalho.

O uso do espaço é avaliado por profissionais altamente qualificados, com qualificações acadêmicas em supervisão e avaliação pedagógica e na disposição de serviços prestados aos alunos no ensino, e os princípios e diretrizes de SUS são utilizados como orientação do plano curricular (GALVÃO EA e SOUSA MF, 2012).

Com todos os exemplos que temos de formas de trabalhar saúde pública nas escolas da educação básica brasileira, a visão fica mais cristalina no sentido de desenvolver novas práticas e implementar as formas já existentes. Nenhum ser humano desenvolve aptidão para aquilo que não conhece, ou que nunca precisou fazer. Estabelecer um contato próximo do aluno com a prática em saúde pode abrir as portas e desmistificar as dificuldades que são disseminadas através do senso comum.

É muito comum encontrar discentes inclinados a formação médica por influência dos altos salários, mas também é comum encontrar propensos profissionais que se interessaram pela prática. Potencializar esses desejos na pré-escola, e abrir portas do ensino superior para as classes menos favorecidas, trata-se de política pública de saúde (GUSMÃO RC, et al., 2015).

Também, muito se pode observar da integração dos serviços de saúde com a educação superior, que pela necessidade profissional, acontece apenas com instituições de formação profissional, mas que podem florescer ideias mais simples a serem implementadas na educação básica. Pesquisas mostram que desde a década de 1970, a experiência de integrar serviços de ensino superior e saúde foi implementada nas Américas.

Após o processo de descentralização do SUS, a rede de serviços de saúde passou a ser administrada principalmente pelo município, principalmente pela rede básica de saúde. Desde então, as iniciativas do governo federal e estadual para treinamento em saúde e educação continuada começaram a exigir a cooperação dos governos das cidades para integrar efetivamente os cursos de graduação e os programas de educação permanente nos serviços (BARRETO ICHC, et al., 2018).

\section{A saúde como direito fundamental potencializada na educação básica}

Mais de duas décadas se passaram desde que a Constituição da República Federal do Brasil foi promulgada em 1988. Ainda se pode dizer que o debate sobre direitos fundamentais e sua eficácia não se perdeu na questão atual, pelo contrário, infelizmente, considerando a atual realidade, o problema da ineficiência aqui continua a ocupar a agenda de grandes desafios para o país e a sociedade. 
Contudo, no constitucionalismo brasileiro, a Constituição de 1988 toma o princípio da dignidade humana como o maior valor do país de uma maneira muito inovadora, que é o cerne da constituição suprema sobre a qual outros direitos se apoiam. Portanto, os direitos básicos, incluindo os sociais, são os defensores desse princípio. Todavia, a educação é um direito social básico e sua realização garante o gozo da dignidade humana (BOLLMANN MGN e VIEIRA FSC, 2016).

A proteção do direito à saúde é um direito básico e está fortemente protegida na Constituição. Esta é uma garantia forte. Deve-se entender que garantias fortes são válidas e se aplicam aos direitos inerentes aos atributos básicos, portanto, de acordo com as disposições da Constituição, vinculam diretamente o Estado e as entidades públicas. Em relação ao direito à proteção da saúde, existem várias obrigações do Estado. $\mathrm{A}$ responsabilidade do Estado pela realização desse direito, os direitos das pessoas no contexto da saúde e as responsabilidades de todas as partes interessadas devem ser alvo de previsões modernas para enfrentar a evolução que ocorreu e lidar com os desafios atuais e futuros (MONGE C, 2019).

As ações de promoção da saúde ocorrem em diferentes espaços e instituições de tomada de decisão, principalmente nos espaços sociais em que as pessoas vivem. Cidades, locais de trabalho e escolas são os locais onde essas ações são propostas para fortalecer ações e protagonistas em nível local e incentivar a participação intersetorial e social. Nesse sentido, é fundamental a implementação de práticas educacionais voltadas à promoção da saúde, prevenção de danos e problemas de saúde. Desenvolver a prática educacional como uma ferramenta para o desenvolvimento do pensamento crítico dos alunos em relação à saúde, é uma forma de ampliar a margem da disseminação da educação em saúde e permitir que a sociedade conheça seus direitos (DUARTE AP, 2015).

A constituição dispõe que: Art. 196. A saúde é direito de todos e dever do Estado, garantido mediante políticas sociais e econômicas que visem à redução do risco de doença e de outros agravos e ao acesso universal e igualitário às ações e serviços para sua promoção, proteção e recuperação.

Art. 197. São de relevância pública as ações e serviços de saúde, cabendo ao Poder Público dispor, nos termos da lei, sobre sua regulamentação, fiscalização e controle, devendo sua execução ser feita diretamente ou através de terceiros e, também, por pessoa física ou jurídica de direito privado.

Art. 198. As ações e serviços públicos de saúde integram uma rede regionalizada e hierarquizada e constituem um sistema único, organizado de acordo com as seguintes diretrizes: I - descentralização, com direção única em cada esfera de governo; II - atendimento integral, com prioridade para as atividades preventivas, sem prejuízo dos serviços assistenciais; III - participação da comunidade.§ 1‥ 0 sistema único de saúde será financiado, nos termos do art. 195, com recursos do orçamento da seguridade social, da União, dos Estados, do Distrito Federal e dos Municípios, além de outras fontes (BRASIL, 1988).

Para compreender a necessidade de se trabalhar direitos fundamentais em uma sala de aula, é preciso antes atentar para a necessidade de instruir socialmente as futuras gerações para garantir que elas cobrem aquilo que Ihes é de direito do Estado. Uma pessoa que não sabe que o Estado é obrigado a Ihe fornecer serviços de saúde pública, acaba acreditando que quando recebe um tratamento digno, está sendo beneficiada, quando na verdade ela é quem financia a prestação daquele serviço.

Por muito se discutiu a inserção de noções básicas de direito constitucional nas salas de aula do ensino médio, o que poderia promover uma grande revolução na educação brasileira e na forma de vida que levamos, garantindo mudanças de hábitos em inúmeros outros campos, e servindo inclusive de instrumento no combate a corrupção (SILVEIRA AAD, 2010). Em uma sala de aula, quando se trata do direito fundamental á saúde, inúmeras portas se abrem e muitas possibilidades acontecem. Um aluno que pouco sabe dos preceitos básicos da saúde nacional, pode além de conhecer o porque dela ser necessária, sentir-se chamado para fazer parte desse meio profissional. O problema central está na forma como se aborda e de que maneira as profissões são apresentadas à sociedade. 
Conhecer a história das profissões, entender a função que cada uma exerce na sociedade e, quando se tratar de matéria de direito fundamental, compreender que é um direito de todos e que o Estado possui a tutela e a obrigação para promover, mudará completamente os rumos de uma sociedade passiva, sem conhecimento e que age quase que por instinto (BOMFIM AMA, et al., 2015).

\section{CONSIDERAÇÕES FINAIS}

Pode-se considerar, portanto, que para despertar novos profissionais para à saúde pública, dedicados e com desejo real pela profissão, através da educação básica, é necessário garantir o conhecimento amplo e a informação correta. Não basta mencionar sem dar margem, ou mecanizar os instrumentos de ensino, é preciso dar margem de conhecimento. Através do direito fundamental à saúde e a educação, pode-se considerar que é direito do cidadão, por ora do aluno, a educação em saúde no ensino básico, já que além de tudo, o direito à justiça social e aos direitos humanos estão presentes de igual maneira na carta magna, ampliando e justificando ainda mais a necessidade de se trabalhar temáticas tão necessárias nas salas de aula.

\section{REFERÊNCIAS}

1. BARRETO ICHC, et al. Integração de instituições de ensino superior com sistemas municipais de saúde à luz de uma tipologia da colaboração interprofissional. Interface - Comunicação, Saúde, Educação, 2018; 22(1): 1365-1376.

2. BATISTA KBC, GONÇALVES OSJ. Formação dos profissionais de saúde para o SUS: significado e cuidado. Saúde e Sociedade, 2011; 20(4): 884-899.

3. BOLLMANN MGN, VIEIRA FSC. Direito fundamental à educação pública de qualidade: efetividade segundo os parâmetros do custo do aluno qualidade inicial. Revista do programa de pós-graduação em educação - UNISUL, 2016; 10(1): 235-252.

4. BOMFIM AMA, et al. Recurso lúdico no processo de educação em saúde em crianças de escolas públicas de Alagoas: relato de experiência. Interfaces -Revista de Extensão, 2015; 3(1): 117-121.

5. BRASIL, 1988. Constituição da República Federativa do Brasil: promulgada em 5 de outubro de 1988. 4. ed. São Paulo: Saraiva, 1990.

6. COMES Y, et al. A implementação do Programa Mais Médicos e a integralidade nas práticas da Estratégia Saúde da Família. Ciência \& Saúde Coletiva, 2016; 21(9): 2729-2738.

7. DUARTE AP. Práticas educativas em saúde no ambiente escolar: uma proposta de intervenção. TCC (Curso de Especialização em Estratégia Saúde da Família). Universidade Federal do Triângulo Mineiro, Uberaba, 2015; 31 p.

8. GALVÃO EA, SOUSA MF. As escolas técnicas do SUS: que projetos político-pedagógicos as sustentam?. PhysisRevista de Saúde Coletiva, 2012; 22(2): 1159-1189.

9. GUSMÃO RC, et al. Tematizar o impacto na educação pelo trabalho em saúde: abrir gavetas, enunciar perguntas, escrever. Interface - Comunicação, Saúde, Educação, 2015; 19(1): 695-707.

10. LOPES IE, et al. Eixos de ação do Programa Saúde na Escola e Promoção da Saúde: revisão integrativa. Saúde debate, 2018; 42(118): 773-789.

11. MAINARDI N. Educação em Saúde: problema ou solução?. Tese (Pós-Graduação em Saúde Pública). Universidade de São Paulo, São Paulo, 2010; 135 p.

12. MARTINS I. Educação em Ciências e Educação em Saúde: breves apontamentos sobre histórias, práticas e possibilidades de articulação. Ciência \& Educação (Bauru), 2019; 25(2): 269-275.

13. MONGE C. O direito fundamental à proteção da saúde. e-Pública: Revista Eletrónica de Direito Público, 2019; 6(1): 75-100.

14. OLIVEIRA APC, et al. Desafios para assegurar a disponibilidade e acessibilidade à assistência médica no Sistema Único de Saúde. Ciência \& Saúde Coletiva, 2017; 22(4): 1165-1180.

15. OLIVEIRA FPSL, et al. Percepção de escolares do ensino fundamental sobre o Programa Saúde na Escola: um estudo de caso em Belo Horizonte, Brasil. Ciência \& Saúde Coletiva, 2018; 23(9): 2891-2898.

16. OLIVEIRA RS, et al. Atuação do enfermeiro nas escolas: desafios e perspectivas. Revista Gestão \& Saúde, 2018; 18(22): $10-22$.

17. RODRIGUES DA, et al. Práticas educativas em saúde: o lúdico ensinando saúde para a vida. Rev. Ciênc. Saúde Nova Esperança, 2015; 13(1): 84-89.

18. SILVA JP, et al. Promoção da saúde na educação básica: percepções dos alunos de licenciatura em enfermagem. Revista Gaúcha de Enfermagem, 2018; 39(1): 1-11.

19. SILVEIRA AAD. A busca pela efetividade do direito à educação: análise da atuação de uma Promotoria de Justiça da Infância e Juventude do interior paulista. Educar em Revista, 2010; 2(1): 233-250.

20. SORATTO J, et al. Insatisfação no trabalho de profissionais da saúde na estratégia saúde da família. Texto Contexto Enferm, 2017; 26(3): 1-11.

21. STUTZ BL, JANSEN AC. Ensino técnico na área da saúde: os desafios do processo de aprendizagem. Psicologia Escolar e Educacional, 2006; 10(2): 211-222.

22. TAVARES MFL, et al. a promoção da saúde no ensino profissional: desafios na Saúde e a necessidade de alcançar outros setores. Ciência \& Saúde Coletiva, 2016; 21(6): 1799-1808. 